\title{
FLEXURAL BEHAVIOR OF TWO-WAY SOLID SLABS REINFORCED WITH GFRP BARS
}

\author{
Hesham A. Haggag \\ Associate Professor, Civil Engineering department, \\ Faculty of Engineering, Helwan University, Egypt \\ Mostafa M. Abd Elsalam \\ Researcher, Faculty of Engineering, Helwan University, Egypt
}

\begin{abstract}
This thesis presents an investigation of the flexural behavior of two-way solid slabs reinforced with GFRP bars. That study is done through experimental and Numerical works. The experimental work includes eight slab specimens, reinforced with GFRP bars in addition to a reference slab, reinforced with steel bars. All slabs have dimensions of $175 \times 175 \mathrm{~mm}$ where the clear spans of all slab specimens are 135x135m. Marginal beams are built at the edges of the slabs with dimension of $200 \times 200 \mathrm{~mm}$. The beams are reinforced with steel bars. The specimens are divided into two groups $(A$, and $B)$ with slab thicknesses of 60 and $70 \mathrm{~mm}$. The slabs are loaded by a loading system which apply uniform loads on the slabs. The loads are applied till the failure of the slabs. The changing parameters are the slab thicknesses of $60 \mathrm{~mm}$ for group A and $70 \mathrm{~mm}$ for group B, and the reinforcement ratio of $0.53 \%$, $1.33 \%, 1.58 \%, 2.31 \%$ for group $A$, and $0.58 \%, 0.77 \%, 0.79 \%$, and $1.01 \%$ for group $B$ while the control slab has thickness of $70 \mathrm{~mm}$ and reinforcement ratio of $0.79 \%$. The measurement parameters are the loads, the corresponding displacements, the strains in the reinforcement bars, in addition to the cracks propagations. The study investigate the load-deflection relations, the load-strain relations in addition to the cracks propagation. Also, the ductility characteristics are evaluated though the displacement ductility factors of each specimen.
\end{abstract}

The experimental results showed that using GFRP bars as reinforcement for the two-way concrete slabs instead of the traditional steel bars is feasible and reliable since they achieved almost similar results. By increasing the slab thickness from 60 $\mathrm{mm}$ to 700 , the slab ultimate capacity is increased by $10 \%$ for slabs with the same reinforcement ratio (0.53\%). It is found that to achieve the ultimate load and the serviceability deflation of the GFRP slabs you may need to increase the reinforcement ratios by $77 \%$ and $22 \%$ of the steel bar slabs. The tested slabs achieved a displacement ductility factor of (2.11 to 3.8) while the control slabs has a factor of 2.11.

Numerical investigations are done on the tested specimens using the ANSYS software. The results are almost similar to the experimental findings. In addition a 
parametric study is done on another 18 specimens investigated numerically only. The changing parameters are the width of the marginal beams, $(200,150,100) \mathrm{mm}$. It is found that changing the marginal beam width has an effect on the slab ultimate loads. Since the ultimate loads decreased by $\sim 13 \%$ by changing the marginal beam width from $200 \mathrm{~mm}$ to $150 \mathrm{~mm}$. Also, that load is decreased by $\sim 30 \%$ by changing the marginal beam width from $200 \mathrm{~mm}$ to $100 \mathrm{~mm}$.

Keywords: Flexural behavior, Solid slabs, GFRP bars, ANSYS.

Cite this Article: Hesham A. Haggag and Mostafa M. Abd Elsalam, Flexural Behavior of Two-Way Solid Slabs Reinforced with GFRP Bars. International Journal of Civil Engineering and Technology (IJCIET), 11(1), 2020, 288-303.

https://iaeme.com/Home/issue/IJCIET?Volume=11\&Issue $=1$

\section{INTRODUCTION}

Fiber Reinforced Polymers, FRP, bars are manufactured to reinforce concrete structures instead of the traditional steel bars. The advantages of using such material are: non corrosive, light weight, none electric conductor, easy manufacture and etc. In the other hand, the traditional steel reinforcement bars may have some disadvantages such as: corrosion, complicated manufacture procedures, electric conductors, and etc.. That is pronounced in structures exposed to harsh environments like roofs, liquid reservoirs, parking areas, bridges, foundations and ...etc. So, many researches are focused on studying the behavior of using FRP bars as reinforcement of concrete sections instead of the traditional steel bars. In addition the design procedures for such structures have been modified accordingly to achieve safely the strength, ductility, and serviceability for the structural elements. It is required to study the behavior of the bars material and their interactions with the concrete material. FRP is a composite material made of a polymer matrix reinforced with fibers. The fibers are usually glass, carbon, aramid, or basalt. Our research is focused on using the Glass Fiber Reinforced Polymers, GFRP, bars to reinforce concrete structures instead of steel bars. In contrary, one may consider many disadvantages needs to be resolved by using such material. GFRP bars have lower modulus of elasticity ( $\sim 5 \mathrm{GPa})$ as compared with the steel ( 196 GPA) and carbon $(\sim 140 \mathrm{GPa})$ material. That could lead to large deformation of the reinforcement structural elements. Also, the bonding with the concrete material should be improved. In addition, they maybe suffer a higher cost than for the conventional steel bars due to the limitation of their use.

\section{OBJECTIVES}

The behavior of concrete slabs reinforced with GFRP bars are investigated for the issue of providing some guide lines for the design of such structures. The flexural behavior is examined for the two-way concrete slabs reinforced with the GFRP bars. Their behavior is evaluated through studying several parameters like the slab thickness, the reinforcement ratios, and the bar diameters. The strength and serviceability are compared with similar slabs reinforced with traditional steel bars and corrections are advised for the design of concrete GFRP reinforced element. The investigation is done experimentally and verified with a reliable numerical model using ANSYS software. Another parameters are investigated numerically only after verification of the numerical models.

\section{EXPERIMENTAL PROGRAM}

The studying program includes testing of eight slab specimens reinforced with GFRP bars, in addition to a concrete slab reinforced with steel bars as a reference specimen. The specimens 
are divided into two groups A and B. Each group consisted of four specimens. The slabs are built with dimensions of $1750 \times 1750 \mathrm{~mm}$. Their thicknesses are $60 \mathrm{~mm}$ for group A and 70 $\mathrm{mm}$ for group B. Edge beams are formed at the perimeters of the slabs with a cross section dimension of $200 \times 200 \mathrm{~mm}$. The clear cover to the reinforcement is $5 \mathrm{~mm}$ for group A specimens and is $10 \mathrm{~mm}$ for group B specimens. The title of each specimen declared its specifications. For example, specimen, "S70 F10@200" has a $70 \mathrm{~mm}$ in thickness, reinforced with glass fiber bars, F, and the has bar diameter of $10 \mathrm{~mm}$ spaced at $200 \mathrm{~mm}$ in apart. The steel bars in the control specimens used the letter, T. Table 1 shows the specifications of the tested specimens whereas, Figure 1 presents the details of the specimens. You may consider that the clear span between the edge beams is $1350 \mathrm{~mm}$. The values are set in the table exactly as fabricated for each specimen.

Table 1 Details of the tested specimens (clear span $=1350 \mathrm{~mm})$

\begin{tabular}{|c|c|c|c|c|c|c|c|c|}
\hline $\begin{array}{c}\text { Specimen } \\
\text { No. }\end{array}$ & Title & $\begin{array}{c}\text { Slab } \\
\text { thick. }\end{array}$ & Cover & $\begin{array}{c}\text { No. of } \\
\text { bars / } \\
\text { width }\end{array}$ & $\begin{array}{c}\text { Bar } \\
\text { diam. }\end{array}$ & $\begin{array}{c}\text { Bar } \\
\text { spacing }\end{array}$ & No/m & Rft ratio \\
\hline S1 & S60 F08@ 200 & 60 & 5 & 7 & 8 & 200 & 5.00 & $0.53 \%$ \\
\hline S2 & S60 F10@ 131 & 60 & 5 & 11 & 10 & 131 & 7.63 & $1.33 \%$ \\
\hline S3 & S60 F12@ 166 & 60 & 5 & 9 & 12 & 166 & 6.02 & $1.58 \%$ \\
\hline S7 & S60 F12@114 & 60 & 5 & 12 & 12 & 114 & 8.77 & $2.31 \%$ \\
\hline S4 & S70 F08@166 & 70 & 10 & 9 & 8 & 166 & 6.02 & $0.58 \%$ \\
\hline S5 & S70 F08@ 125 & 70 & 10 & 10 & 8 & 125 & 8.00 & $0.77 \%$ \\
\hline S6 & S70 F10@ 200 & 70 & 10 & 7 & 10 & 200 & 5.00 & $0.79 \%$ \\
\hline S8 & S70 F10@ 156 & 70 & 10 & 9 & 10 & 156 & 6.41 & $1.01 \%$ \\
\hline S9 & S70 T10@ 200 & 70 & 10 & 7 & 10 & 200 & 5.00 & $0.79 \%$ \\
\hline
\end{tabular}
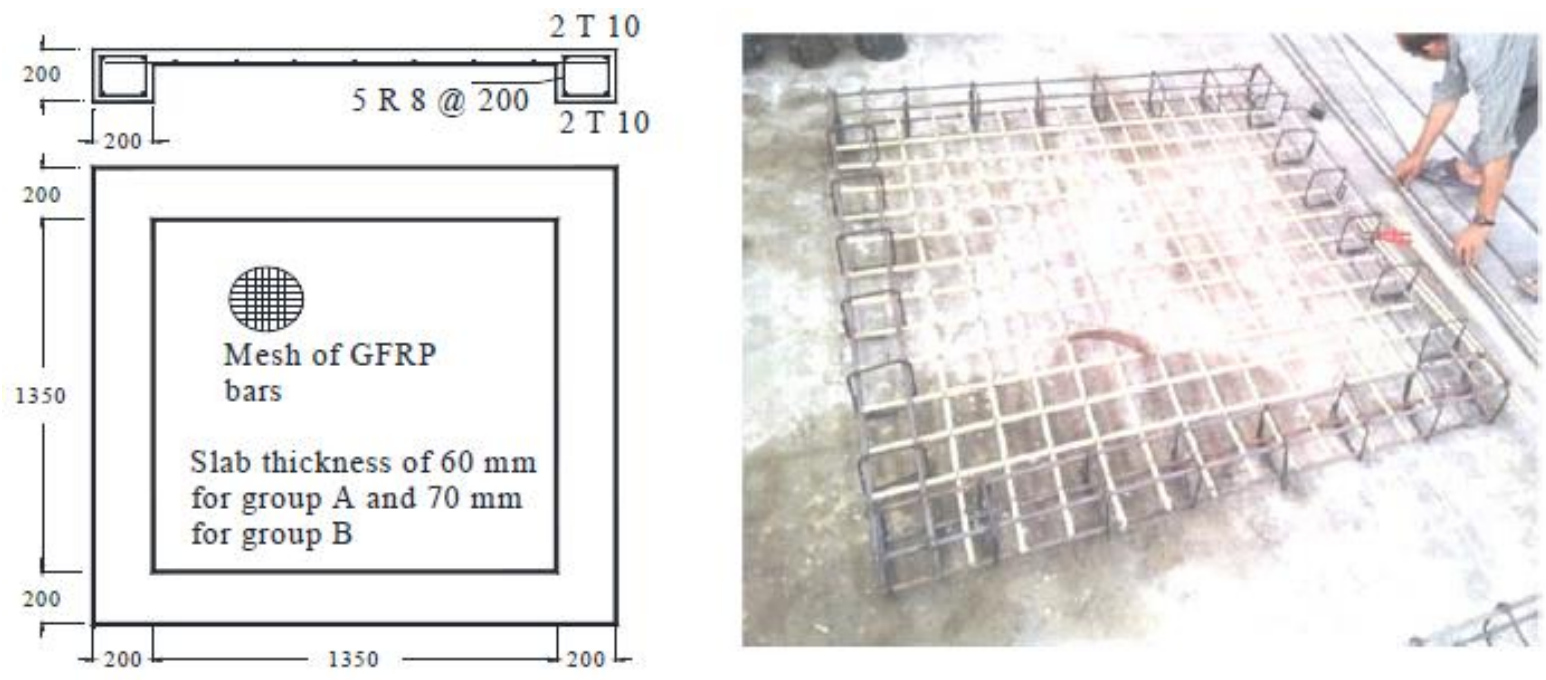

Figure 1 Concrete dimensions and construction of the tested specimens (mm)

\subsection{Test Setup}

A rigid steel frames in the reinforced concrete laboratory, at college of engineering in Helwan University, used to test the specimens. The slabs with their edge beams are supported on stiff steel I-beams. Rubber sheets are used to allow any horizontal motion of the edge beams. A hydraulic jack is utilized to apply the loading action on slabs through a multilevel loading system. The jack loads is transferred to the slabs through five levels which ends to act on sixteen plates placed on the top of the slabs. The loading system is designed to apply the loads equally on each plates. The system was free to rotate at each level to prevent any lateral forces. Some studs are used to keep the stability of the system and prevent any possible 
collapse. Figure 2 shows the testing setup. The loads are applied on the clear span only within an area of (1350X1350) $\mathrm{mm}$. That system needs cares for the setup to prevent any instability. Then the tested slabs are loaded by almost uniformly distributed loads under sixteen thick plates with dimension of $(200 \times 200 \mathrm{~mm})$.
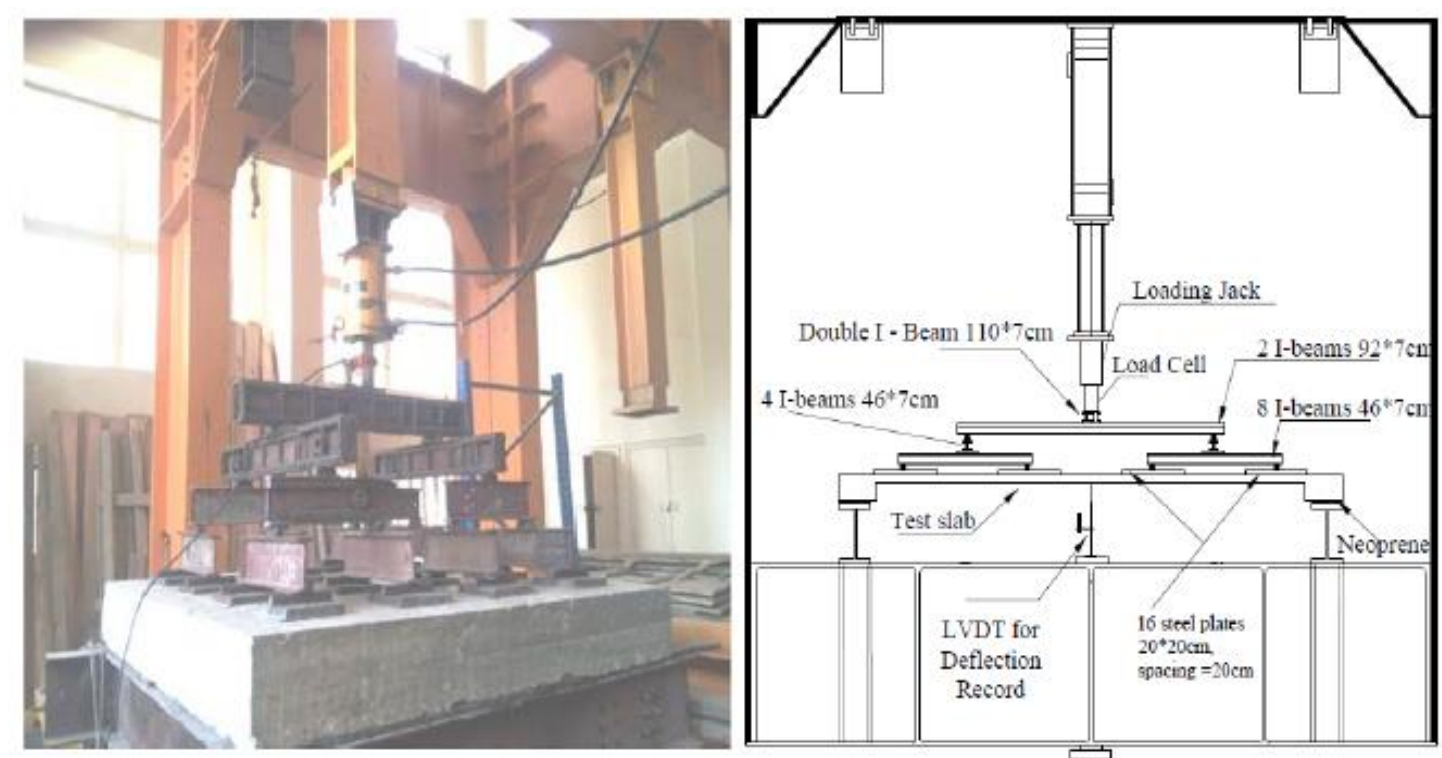

Figure 2: Test setup and loading mechanism

The loading system is designed to maintain it stability during loading and at the failure stage as well. The loads are applied in steps manner and continued till failure of the slabs.

\subsection{Measurements}

The applied loads from the hydraulic jack is recorded through a load cell. Also, the displacements are recorded simultaneously at three points underneath the slab using LVDT measurements. Those LVDTs are place at $(25 \%, 50 \%$, and $75 \%)$ of the clear span of the loaded slabs as shown in Figure. The strains in the reinforcement bars are also measured during testing. Strain gauges are attached to the bar surfaces at the middle section of the slab in two directions. In addition, he cracks are marked and recorded at each loading steps. The loads and deflections are recorded at each loading steps as well.
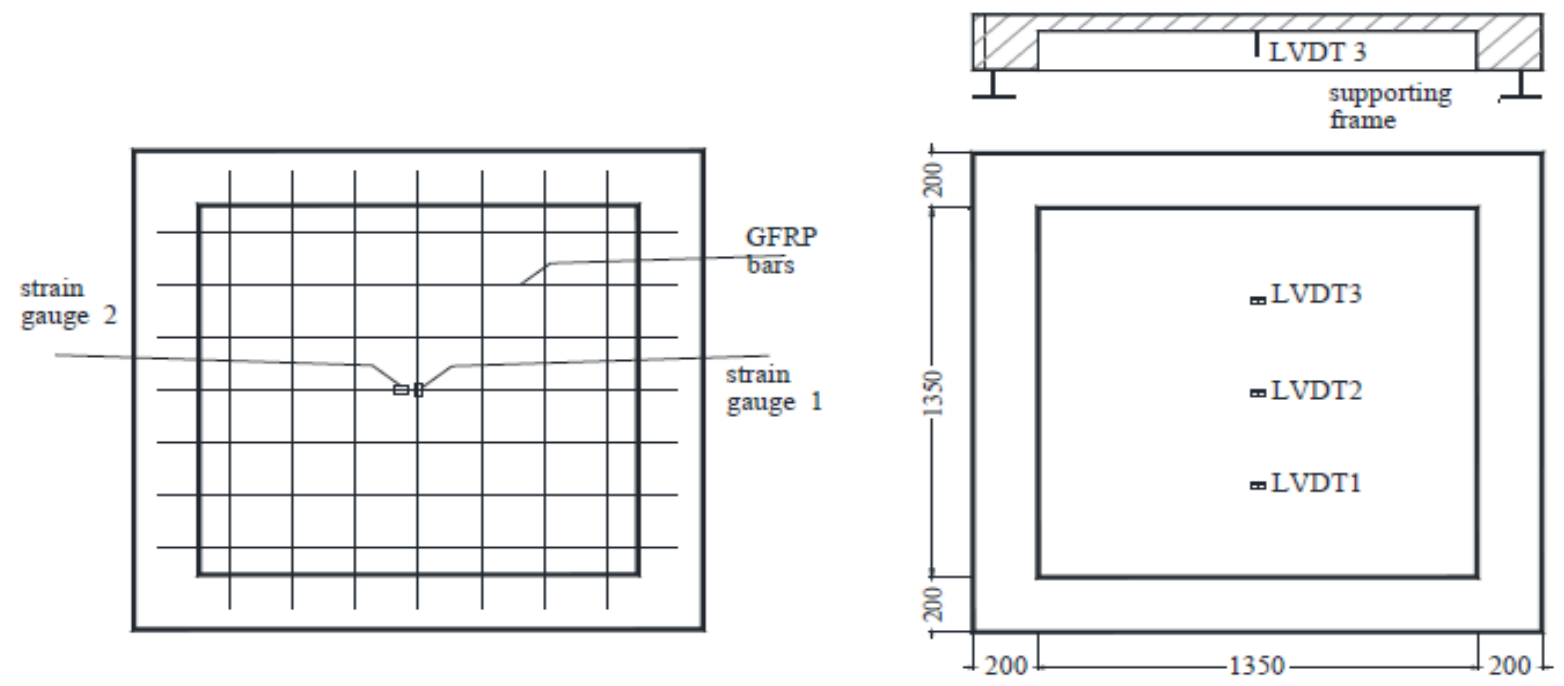

Figure 3: Locations of the strain gauges and the LVDT's 


\section{EXPERIMENTAL RESULTS}

The specimens are loaded in steps till failure. The measurements of the deflections from the LVDTs and the strains from the strain gauges are recorded during the steps of loadings. Also, the cracks propagation along the lower surface of the slabs (the tension side) are marked and recorded. The results of such measurements are presented below.

\subsection{Loads at First Crack and at Failure}

The initial cracking loads and the ultimate loads for groups A and B are presented in Figure 4. Studying that figure one may notice that the cracking and the ultimate loads are increased by increasing the reinforcement ratios for each group. Hence, comparing with the first specimen, S60 F08@200, the cracking loads are increased by 8.4\%, 49.9\%, and 57.2\% for specimens in group A due to increasing the reinforcement ratios by 151\%, 199\%, 335\% respectively. Also, the ultimate loads are increased by $17.5 \%, 21.6 \%$, and $34.9 \%$ for specimens of group A due to increasing the reinforcement ratios by $151 \%, 199 \%$, 335\% respectively. Similarly, comparing with the first specimen in group B, S70 F08@166, the cracking loads are increased by 10\%, 11.9 , and $21.9 \%$, for specimens of group B due to increasing the reinforcement ratios by $32.7 \%, 36.2 \%$, and $74 \%$. Also, the ultimate loads are increased by $7.3 \%, 6.7 \%$, and $25.7 \%$ for specimens of group B due to increasing the reinforcement ratios by $32.7 \%, 36.2 \%$, and $74 \%$ respectively.

One may notice also that changing the bar diameters with the same reinforcement ratios does not effect on the ultimate capacities. All specimens in group B did not achieve the ultimate capacity of the control specimens which have a reinforcement ratio of $0.79 \%$ since the maximum reinforcement ratio utilized in group B is $1.01 \%$.

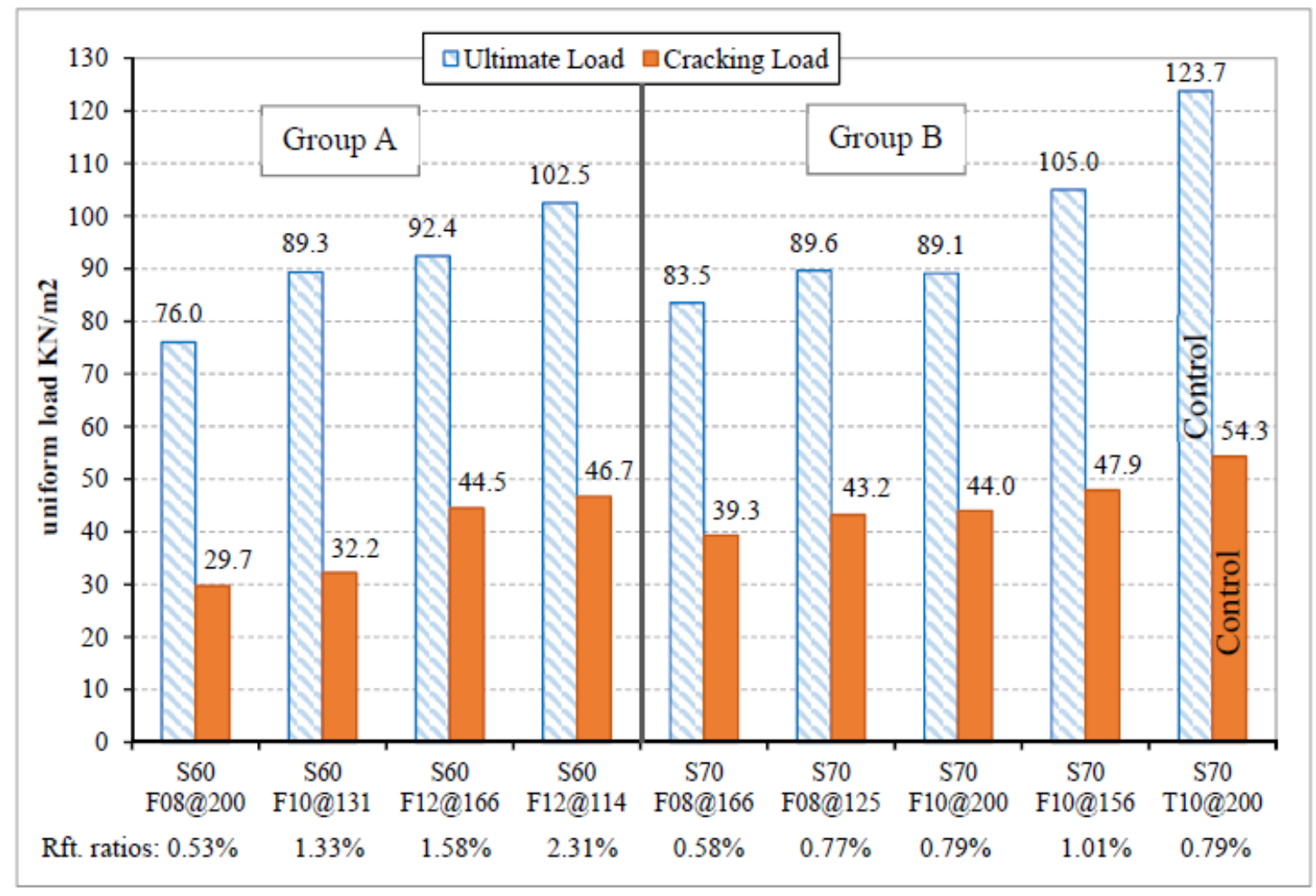

Figure 4: Cracking and ultimate loads for the tested specimens 


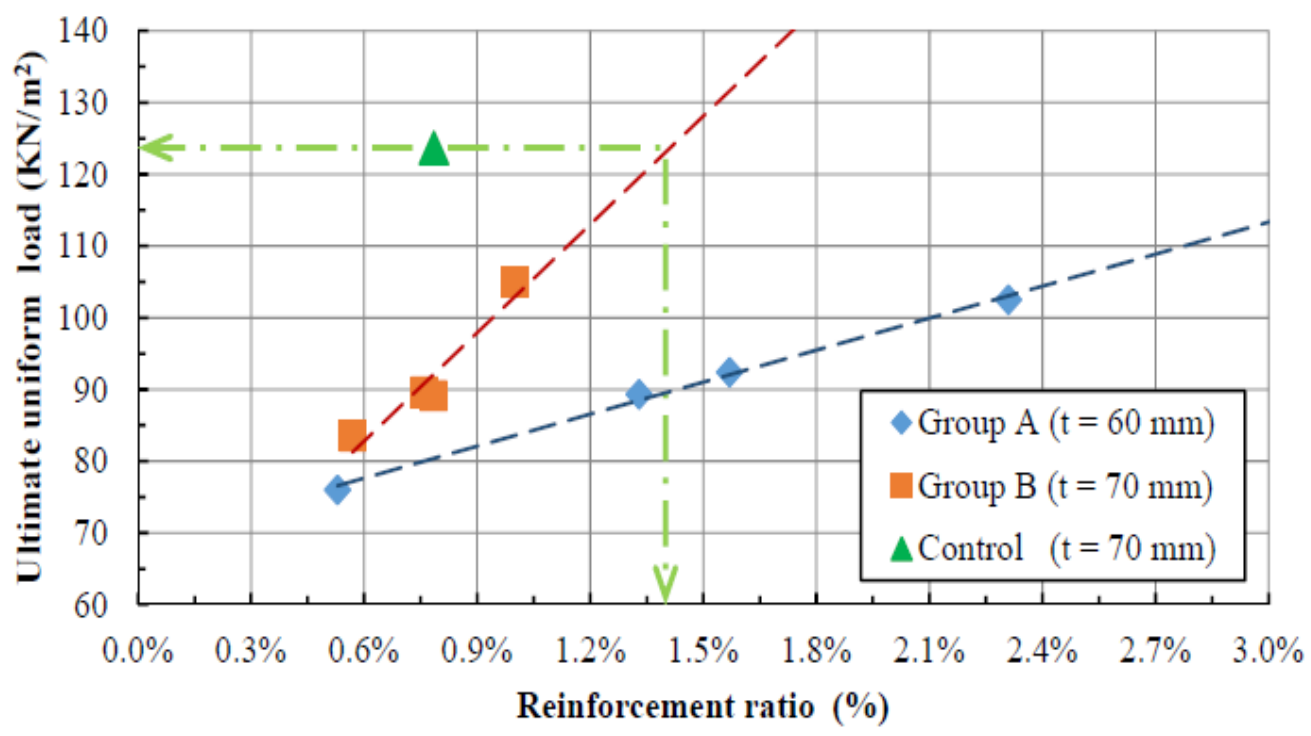

Figure 5: The ultimate capacity in relation to the reinforcement ratios

Further studies showed the relation between the ultimate load and the reinforcement ratios for both groups as shown in Figure 5. Interpolations are made for each group to show the trend of the results of each group. The value of the control specimens is presented also on the same figure. However, the value of the ultimate load of the control specimen $\left(123.7 \mathrm{KN} / \mathrm{m}^{2}\right)$ with reinforcement ratio of $(0.79 \%)$ is not achieved, we may figure out the required reinforcement ratios through the intercept with the corresponding interpolation line. This ratio is found to be $1.4 \%$. Then using GFRP bars instead of steel bars requires an increase of the reinforcement ratio by $77.2 \%$ to achieve the required ultimate load.

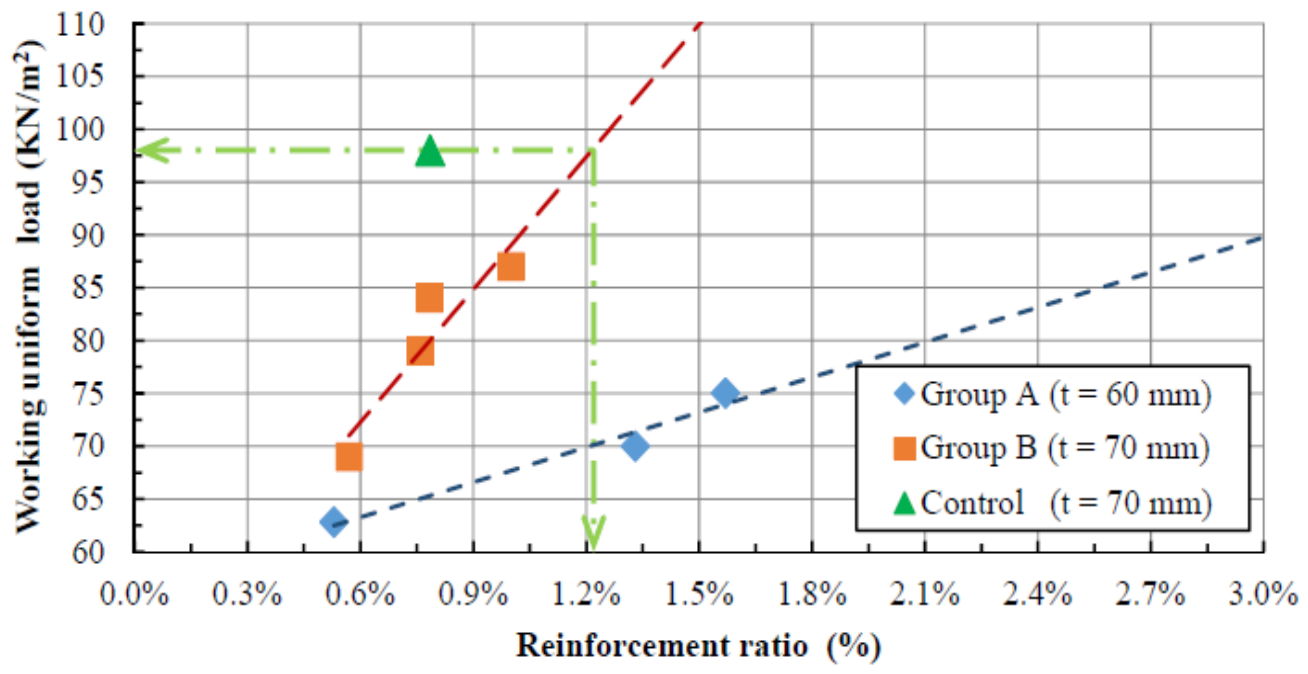

Figure 6: The loads at a deflection of $20 \mathrm{~mm}$ (almost corresponding to the working loads)

A similar relation is prepared at a displacement value of $20 \mathrm{~mm}$ for all specimens. That value almost meets the value of the working load for the control specimen. The interpolation line is graphed also for each group as shown in Figure 6. Then to achieve that value of the working load you may find a reinforcement ratio through the intercept with the shown interpolation line. This ratio is found to be $1.22 \%$. Then using GFRP bars requires an increase of the reinforcement ratio by about $54.4 \%$ to achieve the required working load of a reinforcement ratio of the slab reinforced with steel bars. 
Flexural Behavior of Two-Way Solid Slabs Reinforced with GFRP Bars

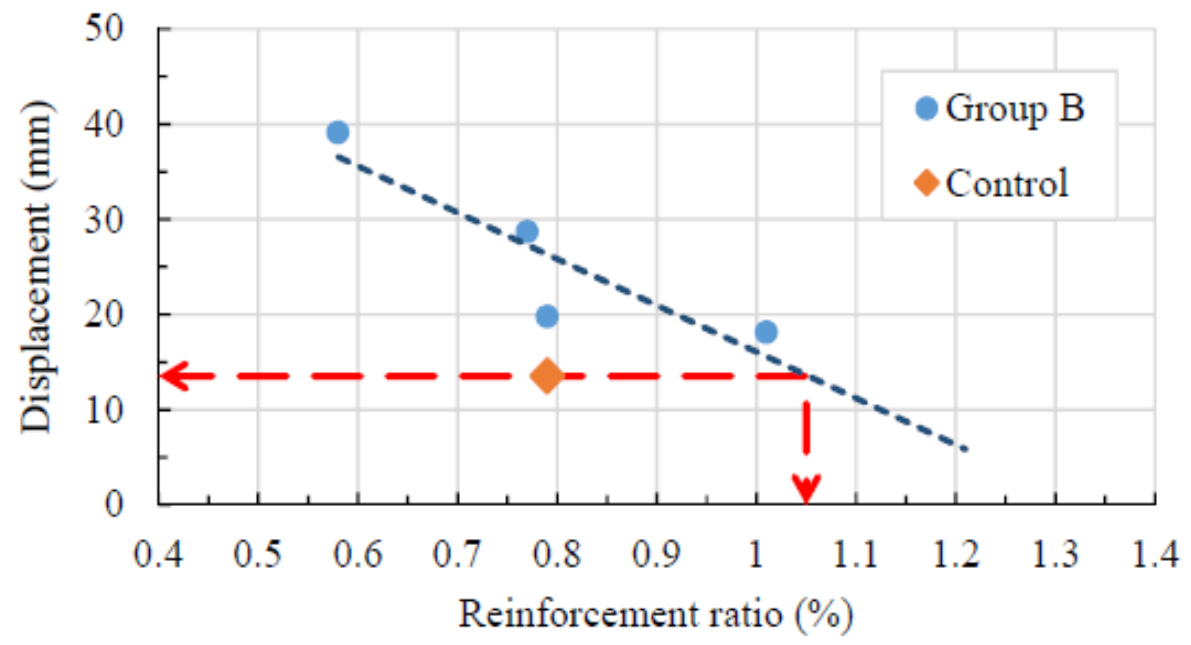

Figure 7: Group B displacements at the working load of the control specimen with slab thickness of $70 \mathrm{~mm}$.

Moreover, the displacements are measured for the specimens in group B at the value of the working loads for the control specimen which equal to $\sim 82 \mathrm{KN} / \mathrm{m}^{2}$. That is graphed in Figure . An Interpolation line is built for the measured values. The displacement of the control specimen at the working loads is displayed and the corresponding value of the reinforcement ratios of the GFRP specimens is found from the interpolation line as shown in that figure. It is found that the reinforcement ratio required for the GFRP specimen is $1.05 \%$ to achieve the working displacement of the control specimen. Then the reinforcement ratio is required to be increased by $33 \%$ than for the steel reinforcement to achieve the required displacement at the working loads.

\subsection{Load-Deflection Relationship}

The deflection at the mid span is graphed with the corresponding acting loads for each specimen and presented in Figure, and Figure for groups A, B. Studying those curves one could notice that all specimens exhibited almost the same pattern until failure. The first parts of the curves are almost linear till the first crack and then nonlinear performance is continue till failure.

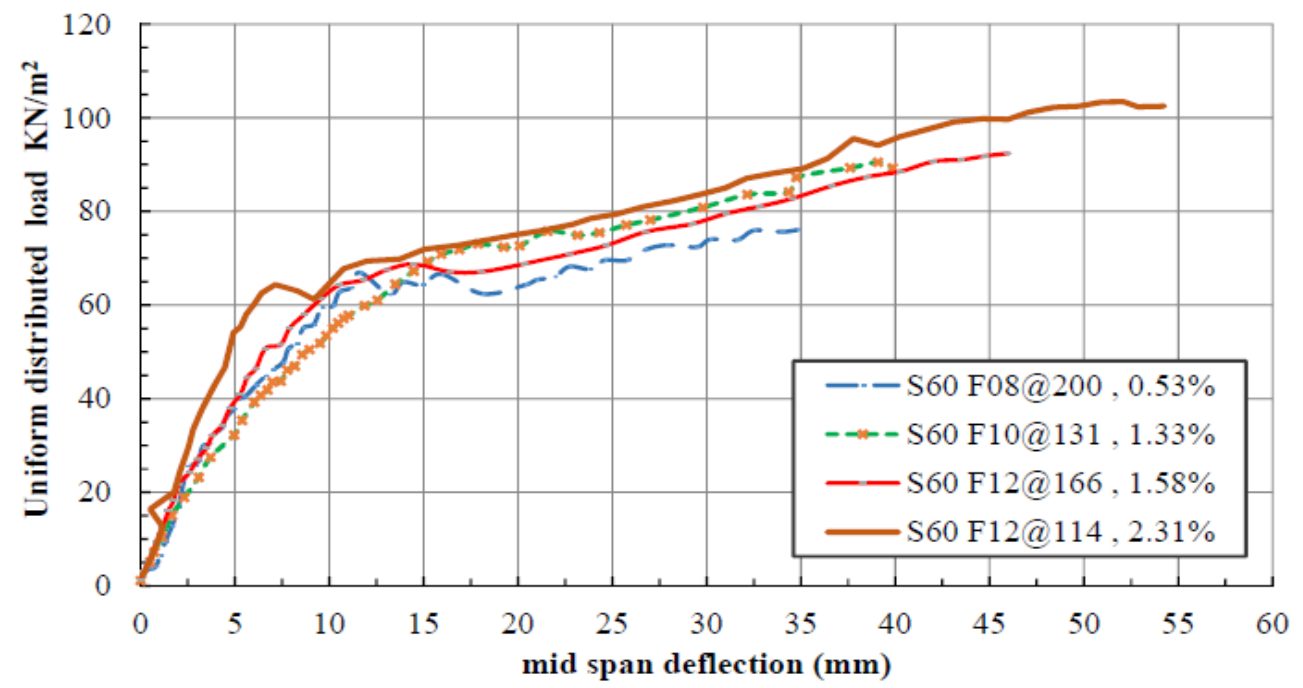

Figure 8: Load- deflection curves for all slabs in group A, with $\mathrm{t}=60 \mathrm{~mm}$ 
Also, the load deflection relations are improved with respect to the initial stiffness and the ultimate loads by increasing the reinforcement ratios for the same thickness. In group B, where the control specimen is tested, specimen S70 F10@156 achieved the best performance to the control specimen. Once more, by using GFRP bars to reinforce two way concrete slabs would require an increase of the reinforcement ratio by $77.2 \%$ (stated before) to achieve the required load-deflection as compared to the reinforcement ratio of a slab reinforced with steel bars.

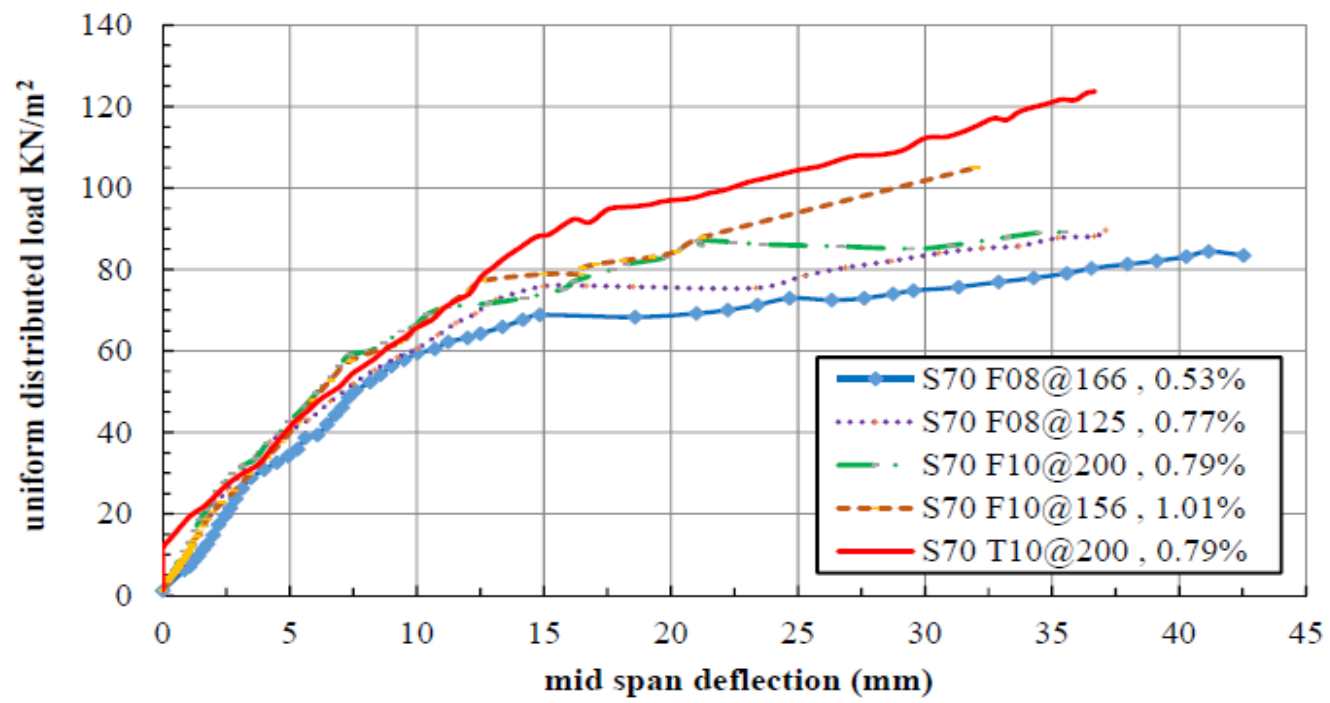

Figure 9: Load- deflection curves for all slabs in group B, with $\mathrm{t}=70 \mathrm{~mm}$

Further studies of the obtained data are done on the ductility performance of the loaddeflection relations for the two way slabs reinforced with GFRP bars. The initial stiffness is calculated for each specimen at the first observed crack. That is presented in Table 2. The yield displacement value is evaluated for each specimen at a loading value of $75 \%$ of its ultimate load whereas the ultimate displacement is taken at the failure load. The displacement ductility factor is drawn and found in Table 2. You may find those specimens achieved ductility in ranges of $\sim(2.11-3.8)$ whereas the control displacement has a ductility factor of 2.26 .

Table 2: Initial stiffness and displacement ductility factor

\begin{tabular}{|c|c|c|c|c|c|}
\hline \multirow{3}{*}{ Group } & Specimen title & $\begin{array}{c}\text { Initial } \\
\text { Stiffness }\end{array}$ & $\begin{array}{c}\text { Yield } \\
\text { displacement }\end{array}$ & $\begin{array}{c}\text { Ultimate } \\
\text { displacement }\end{array}$ & $\begin{array}{c}\text { Ductility } \\
\text { factor }\end{array}$ \\
\cline { 2 - 6 } & & $\mathbf{K N} / \mathbf{m}$ & $\Delta \mathbf{y}(\mathbf{m m})$ & $\Delta \mathbf{u}(\mathbf{m m})$ & $\Delta \mathbf{u} / \Delta \mathbf{y}$ \\
\hline \multirow{3}{*}{$\mathrm{A}$} & S60 F08@200 & 21,380 & 9.50 & 34.82 & 3.67 \\
\cline { 2 - 6 } & S60 F10@ @ 131 & 15,620 & 14.50 & 39.87 & 2.75 \\
\cline { 2 - 6 } & S60 F12@166 & 18,600 & 20.40 & 45.98 & 2.25 \\
\cline { 2 - 6 } & S60 F12@ @ 114 & 25,130 & 21.50 & 54.26 & 2.52 \\
\hline \multirow{3}{*}{ B } & S70 F08@ 166 & 15,760 & 11.20 & 42.54 & 3.80 \\
\cline { 2 - 6 } & S70 F08@ 125 & 18,070 & 11.50 & 37.10 & 3.23 \\
\cline { 2 - 6 } & S70 F10@200 & 20,600 & 9.90 & 35.50 & 3.59 \\
\cline { 2 - 6 } & S70 F10@ @ 156 & 21,140 & 15.10 & 32.00 & 2.11 \\
\hline Control & S70 T10@ 200 & 17,830 & 16.20 & 36.68 & 2.26 \\
\hline
\end{tabular}




\subsection{Cracks Pattern and Mode of Failure}

The cracks are marked on the bottom surfaces of the slabs during the testing loading steps. Figure 1 shows the cracks pattern for each specimen at failure. Studying those figures showed that all specimens experienced flexural failure. While test specimens are loaded, GFRP bars strained under tension forces. First cracking is formed at the mid-span of the lower surface of the slabs where the maximum moment is found. The cracks propagate with increasing the applied loads. After first crack is observed as the load is increased gradually, the cracks propagated towards the corner and widened. The cracks in all specimens propagated in diagonal manner as shown. In general the performance of the two way slabs reinforced with GFRP bars is similar to slabs reinforced with steel bars.
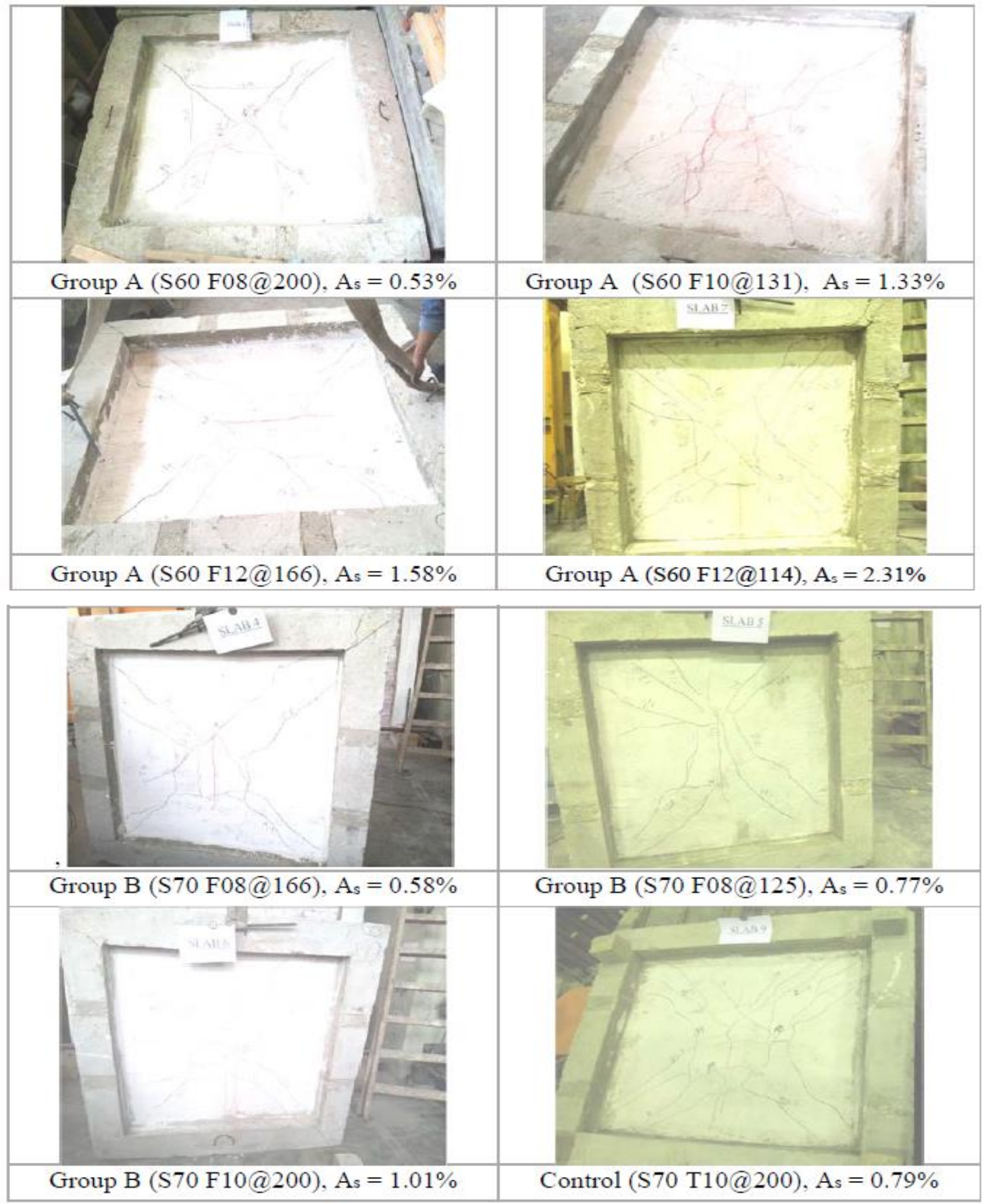

Figure 10: Crack patterns of the tested specimens 


\section{NUMERICAL STUDY USING FINITE ELEMENT PROGRAM (ANSYS)}

Nonlinear finite element program (ANSYS V15.0) is utilized to verify the experimental results for the tested specimens. In addition more parameters are studied after verification of the numerical models. All specimens are modeled and analyzed using that fem program. SOLID 65 element is used to model the concrete material. That element is defined by eight nodes having three degrees of freedom at each node: translations for each node in $\mathrm{x}, \mathrm{y}$, and $\mathrm{z}$ directions. That element has the capability to simulate cracking in tension and crushing in compression. In addition, SOLID 45 is used to model the steel plates for loading distribution over the slabs and also to simulate the supporting system. Sixteen steel plates were used to give well simulation for the uniform distributed load on the two-way slabs. Moreover the LINK 180 is used to model the reinforcement either for steel or GFRP bars. The properties of each material are considered in the analysis as tested in the experimental program. Hinged supports modeled the supporting system along the bottom of the slab marginal beams. The beams are allowed to rotate at supports. The model of the slabs is shown in Figure 11

In current research the main assumptions for the finite element models are: the concrete is modeled as an isotropic and homogeneous materials, the Poisson's ratio is assumed to be constant throughout the loading history and perfect bond is assumed between the GFRP bars and concrete elements.

\subsection{Properties of the used Material}

The material used in fabrication of the testing specimens are examined and their physical properties are used in our analysis. The average ultimate compressive strength of the concrete cubes is $\mathrm{f}_{\mathrm{cu}}=25.2 \mathrm{MPa}$. The nominal diameter of the used steel bars is $10 \mathrm{~mm}$ where the average yield and ultimate strengths are 410 , and $600 \mathrm{MPa}$, consequently. Three diameters are examined for the GFRP bars $(8,10$, and 12) $\mathrm{mm}$. Those bars have an average fiber volume fraction of about $62 \%$. The average modulus of elasticity for GFRP bars and their tensile strength are 46800, and $1230 \mathrm{Mpa}$.
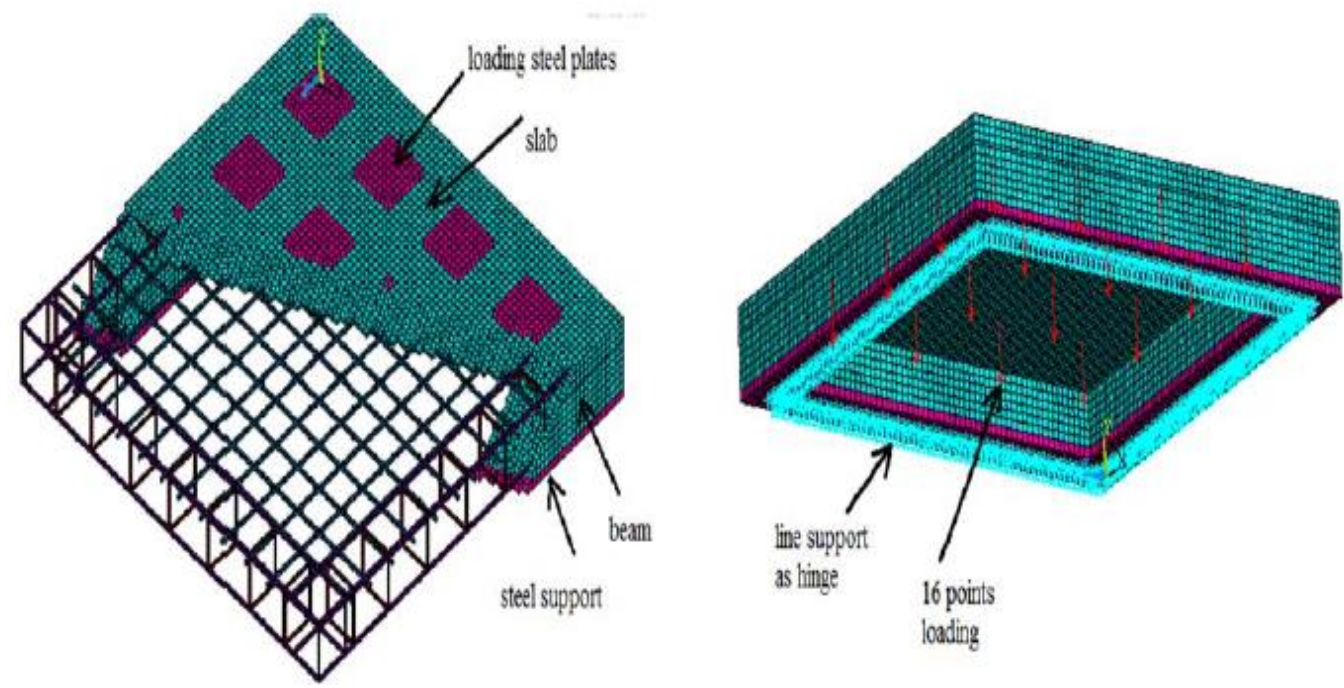

Figure 11: Numerical models of the slabs with the boundary conditions 


\section{RESULTS OF THE NUMERICAL ANALYSIS}

The load is applied on the specimen in step wise manner till failure. The same sequence of loading used for the experimental steps is followed during the numerical loading. Many parameters are recorded during the loading steps. The measured parameters are: the applied loads, the corresponding displacements, the maximum strains and stresses in the reinforcement bars, the deformed shapes and finally, the cracked patterns. Figure 12 shows the output of the first specimen (S60 F08@200). The deformation shape of the slab is presented. Also, the strains in the bottom layer of the concrete element is shown. Also, the strains in the reinforcement bars are displayed.
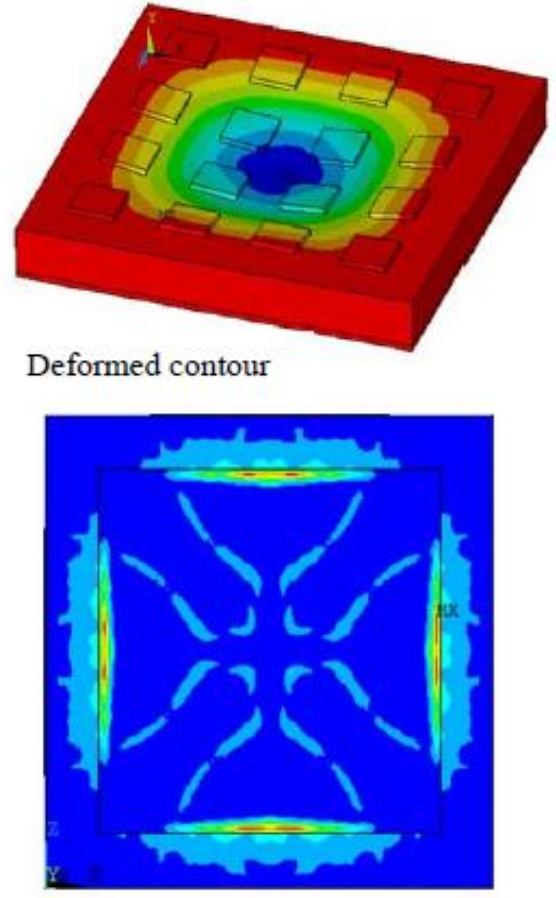

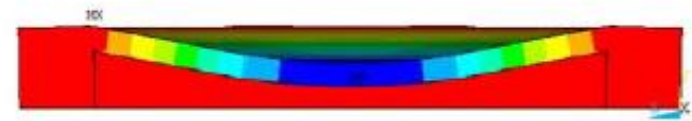

Deformed shape

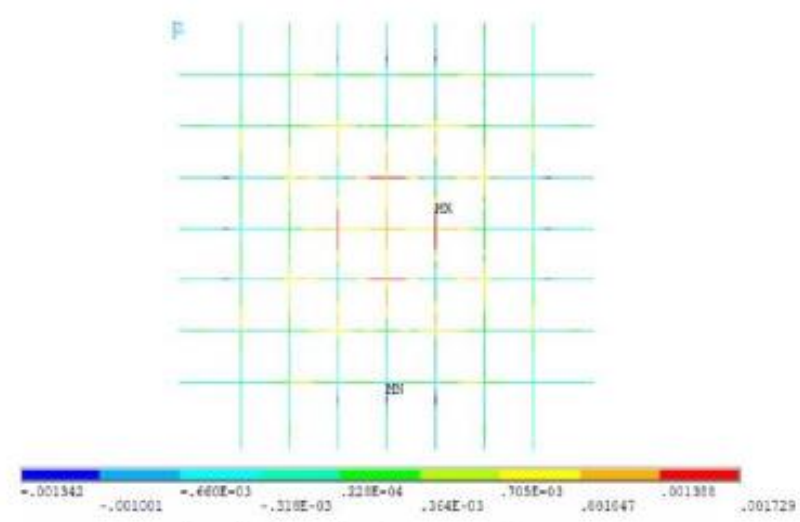

Strains in the reinforcement bars

Figure 12: Slab deformation, stresses, strains at the bottom surfaces of the concrete elements and finally the strain in the reinforcement bars for slab specimen (S60 F08@ 200).

\subsection{Load-deflection relations from the numerical models}

The load-deflection curves are drawn for the specimens with group A, B and the control specimen. The values are verified with the experimental findings. Those relation are presented in Figure 13, Figure 14 and Figure 15. One can notice that all curves in group A are similar to the experimental relation. Also the slopes to the first crack are almost close to the results from the experimental findings. Also, the maximum displacements are close to the experimental results. The results for the control specimens achieved the first slope, the ultimate displacement, and the ultimate loads but the middle part of the curve is a little far from the experimental one. In addition, the initial stiffness calculated by ANSYS program is higher than the experimental results. In group $\mathrm{B}$ the numerical results are almost close to the experimental results. That could lead to the numerical model is reliable and dependable. So, more data can be figured out from that numerical models. In most cases the maximum experimental displacements are close to the numerical values. 
Hesham A. Haggag and Mostafa M. Abd Elsalam

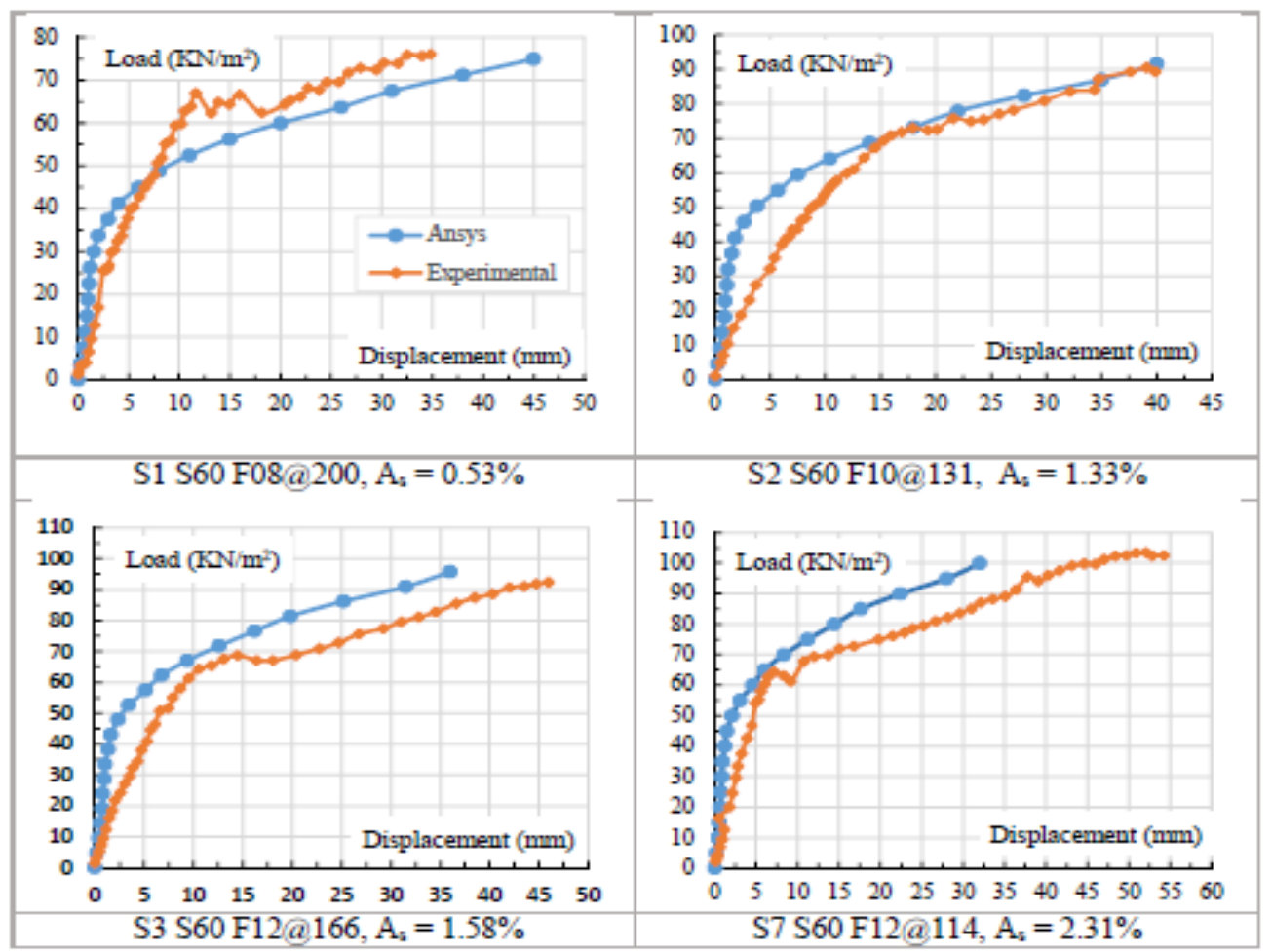

Figure 13: The load-deflection relations from the ANSYS and the experimental findings forgroup (A)

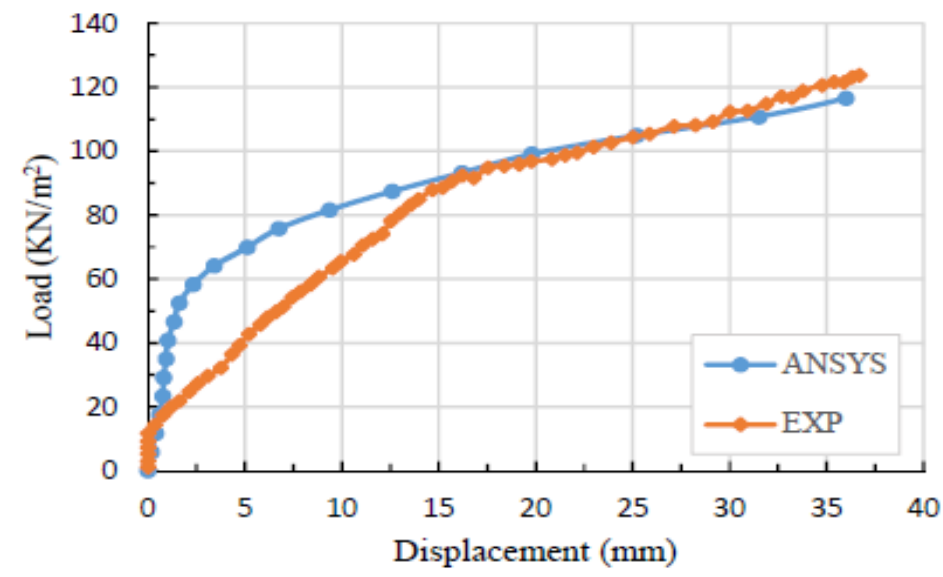

Figure 14: The load-deflection relation from the ANSYS and the experimental findings for the control specimen, S70 T10@200, As = 0.79\%

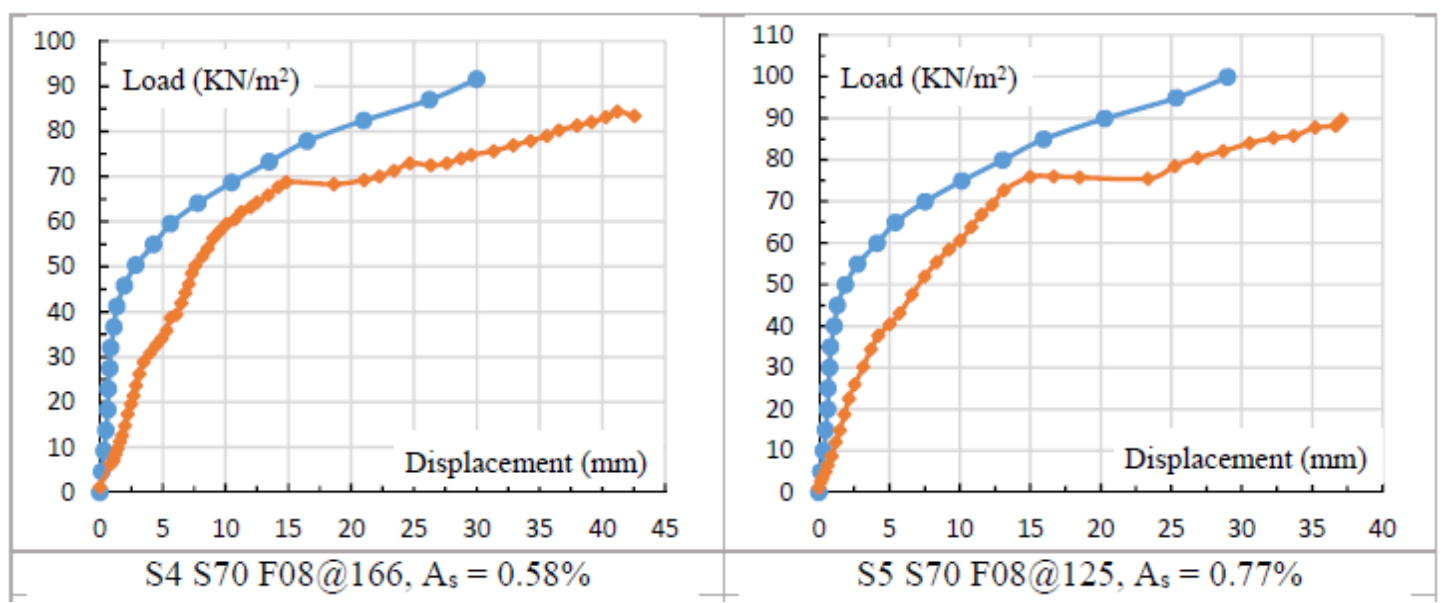


Flexural Behavior of Two-Way Solid Slabs Reinforced with GFRP Bars

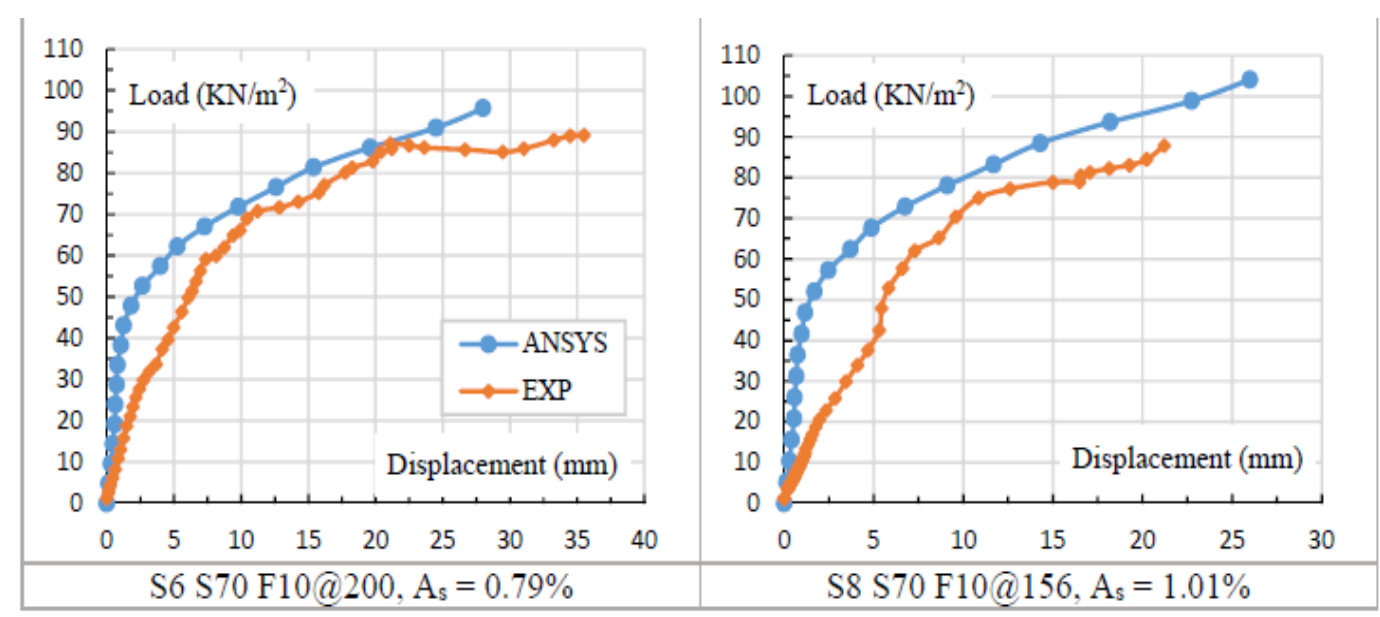

Figure 15: The load-deflection relations from the ANSYS and the experimental findings forgroup (B)

\subsection{Numerical Parametric Studies}

After verifying the numerical models, more parameters are numerically investigated. The effect of the marginal beam size on the testing results are studied. All nine specimens are modeled again with different sizes for the marginal beams. The additional models used marginal beams with dimensions of $150 \times 200$ and $100 \times 200 \mathrm{~mm}$. The beams depth is kept equal to $200 \mathrm{~mm}$ but their widths are varied. The variation of the dimension of the marginal beams is reflected on the variation of the stiffness of the supporting beams. That would have an impact on the loading capacity and the performance of such slabs. The following section will present the results of the additional models after loading with the same loading schemes for the main specimens. The results are compared with the experimental findings. The compared recorded parameters are the ultimate loads, the cracks pattern, the load deflection relation, and finally the strains in the reinforcement bars.

\subsection{Ultimate Loads for different Numerical Models}

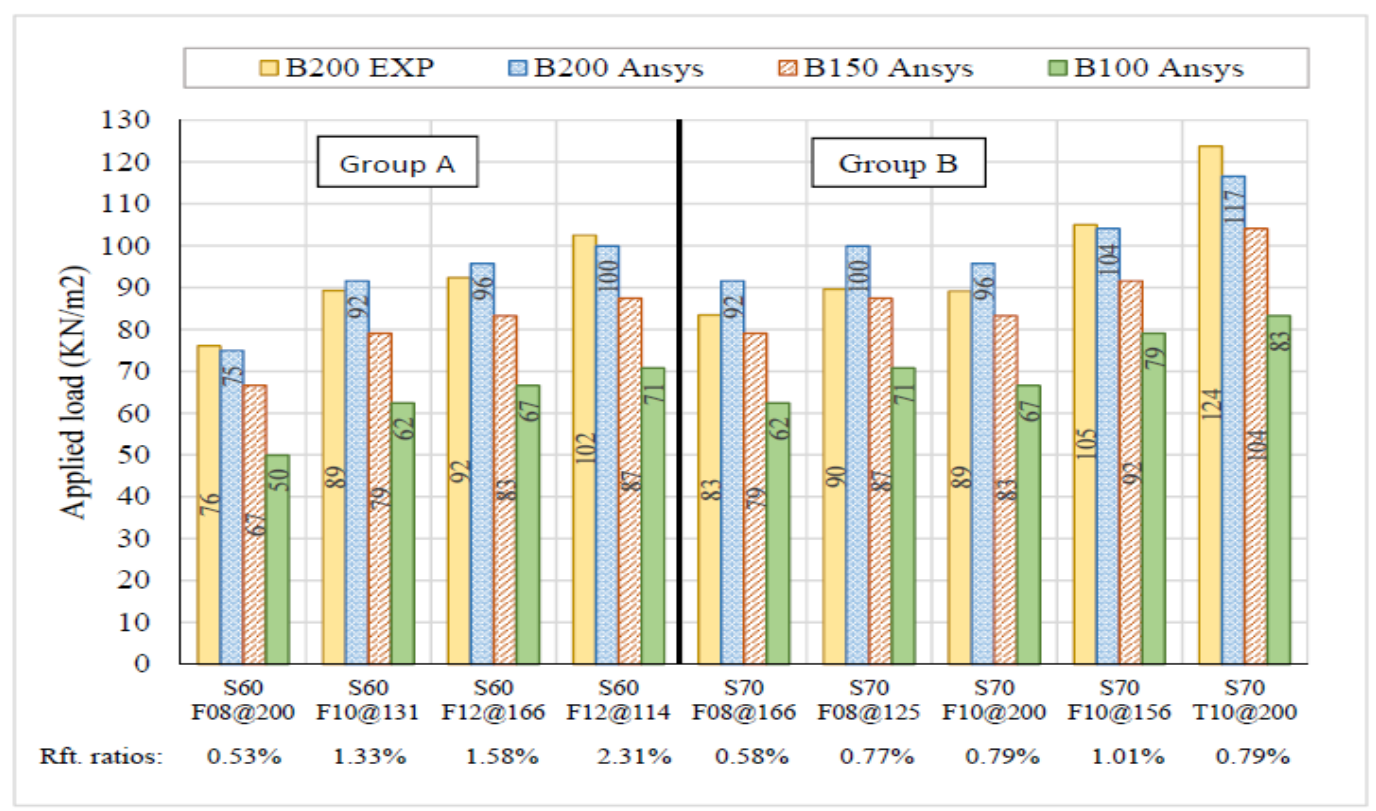

Figure 16: The calculated ultimate loads from the numerical models of slabs with marginal beams widths of 200,150 , and $100 \mathrm{~mm}$ 
The ultimate loads are calculated for each model. Figure shows the ultimate loads for all models with beams widths of 200,150 , and $100 \mathrm{~mm}$. Those values represent $(3.33,2.5,1.67)$ of the slab thickness, $t_{s}$, for group A and $\left(2.8,2.14\right.$, and 1.43) $t_{s}$ for group B specimens. You may notice that the ultimate loads are decreased by $\sim 13 \%$ for groups $\mathrm{A}$ and $\mathrm{B}$ by decreasing the marginal beam width from $200 \mathrm{~mm}$ to $150 \mathrm{~mm}$. Also, the ultimate loads are decreased by $\sim 30 \%$ by decreasing the beam width from $200 \mathrm{~mm}$ to $100 \mathrm{~mm}$. That derive a conclusion of the stiffness of the marginal beams have a great effect on the ultimate loading capacity of the two-way loaded slabs reinforced with GFRP bars.

\subsection{Cracks Pattern}

The cracks pattern are found to be similar to the experimental recorded cracks. Also, the cracks started at the middle part of the lower surface of the slabs and then propagate to the corner of the slabs. We found also that the cracks have better distribution with increasing the reinforcement ratios.

\subsection{Load Deflection Relations}

The load deflection relations are constructed for all specimens with changing the width of the marginal beams to be $b=200,150,100 \mathrm{~mm}$, as shown in Figure . In addition, similar relations for the experimental specimens with marginal beam width of $200 \mathrm{~mm}$ are presented in the same figure. Studying those curves show that by decreasing the width of the marginal beams decrease the stiffness of the supporting system and consequently the ultimate loads are decreased. As shown before the experimental results are close to the model with marginal beams widths of $200 \mathrm{~mm}$. That effect is pronounced with slabs with smaller thickness of $t_{s}=60$ $\mathrm{mm}$. Then the effect is decreased for models with larger slab thickness where the ratio of $b / t_{\mathrm{s}}$ is small. Then researcher should care with building a suitable prototype for slabs supporting systems.

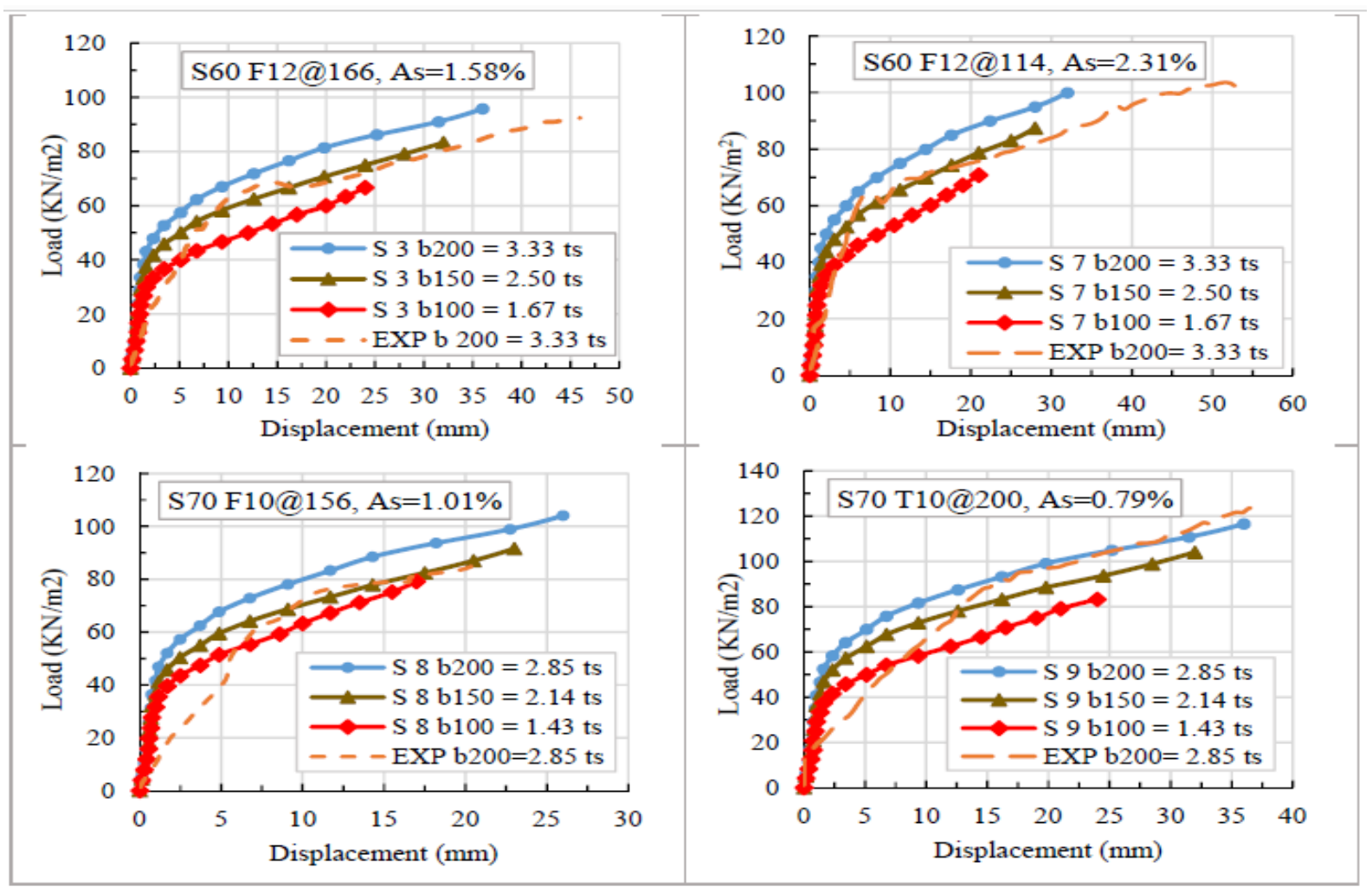

Figure 17: The load deflection relation from the numerical models with different values of the width of the beam supporting system. 


\subsection{Load-Strain Relationship}

The strains in the GFRP reinforced bars are measured and presented in a relation to the applied loads. Those relations are done for the numerical models in addition to the experimental results. Figure shows the results of the numerical models are close to the experimental findings for similar specimens with marginal beam width of $200 \mathrm{~mm}$.
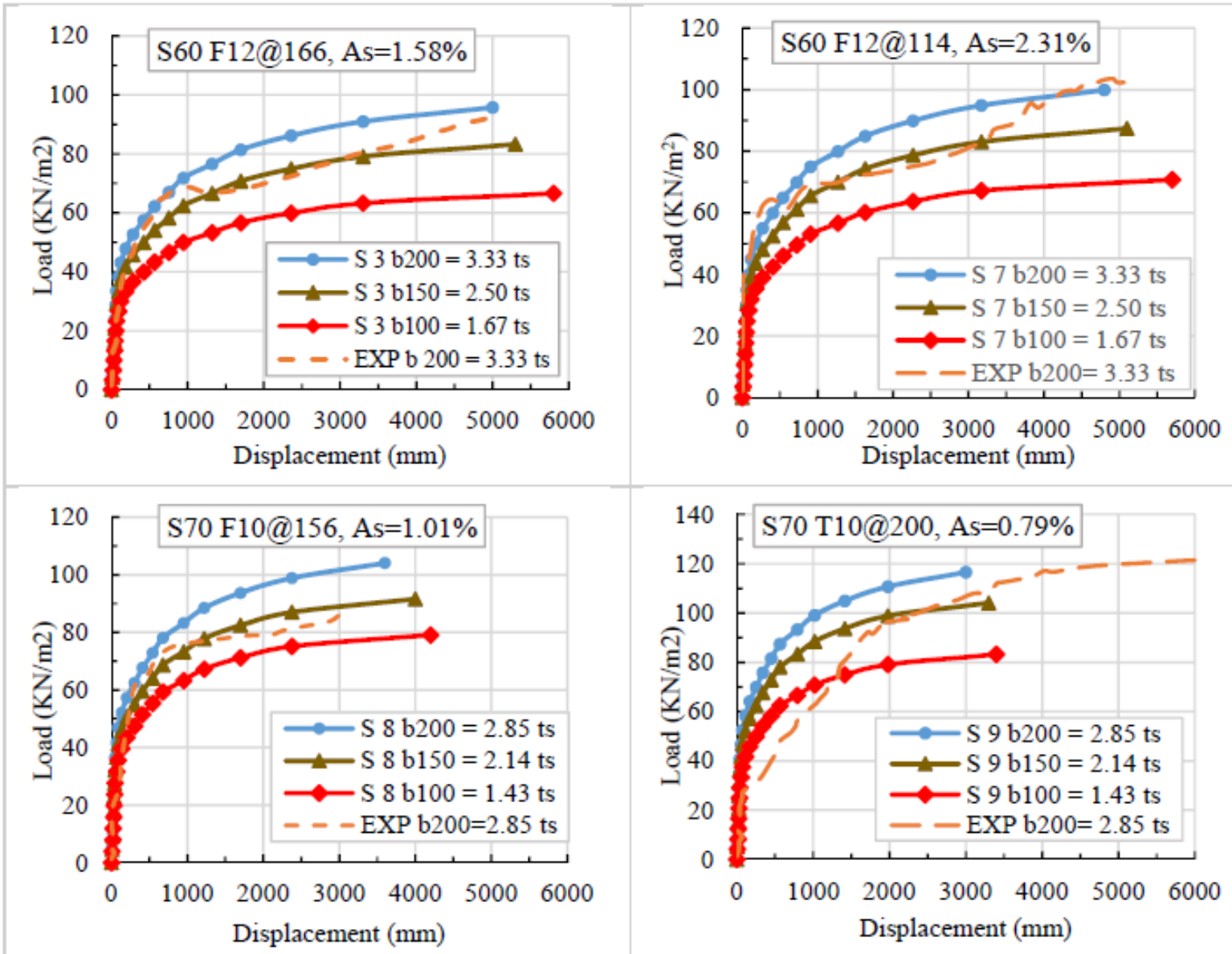

Figure 18: The load strain relationship from the numerical models with different values of the width of the beam supporting system.

\section{CONCLUSIONS}

The analysis of experimental and numerical results of the tested slabs lead to the following conclusions

- Using GFRP bars as reinforcement for the two-way concrete slabs instead of the traditional steel bars is feasible and reliable since they achieved almost similar physical properties.

- Increasing the reinforcement ratio and slab thickness, increases the ultimate capacity and decreases the max deflection for two way solid slabs reinforced with GFRP bars

- Crack pattern for slabs reinforced with GFRP bars has better distribution with increasing the reinforcement ratios.

- GFRP bars in the tested reinforced slabs did not fail in rupture so crushing of concrete forms the mode of failure.

- In GFRP slabs increasing slab thickness by $1 \mathrm{~cm}$, the ultimate capacity is increased by about $10 \%$ with the same reinforcement ratio of about $(0.53 \%)$. 
- Slabs reinforced with GFRP bars with thickness of $70 \mathrm{~mm}$ achieved the ultimate load of the control specimen (steel bar reinforcement) by increasing the reinforcement ratio by $77 \%$.

- Slabs reinforced with GFRP bars with thickness of $70 \mathrm{~mm}$ achieved the displacement at the service loads of the control specimen (steel bar reinforcement) by increasing the reinforcement ratio by $22 \%$.

- The ductility of the control specimens in Group B with slab thickness of $70 \mathrm{~mm}$ and reinforcement ratios of $0.79 \%$ achieved a displacement ductility factor of 2.26 . However similar slabs with lower reinforcement ratios of $(0.58 \%, 0.77 \%, 0.79 \%$, and $1.01 \%)$ achieved a displacement ductility factor of $(3.8,3.23,3.59$, and 2.11$)$ consequently.

- The numerical models using ANSYS software achieved almost similar results for the experimental specimens with respect to the cracking pattern, the load displacement relationship, and the load-strain relationship.

- In general the initial stiffness calculated by ANSYS program are higher than similar tested specimens.

- Using a parametric studies on the numerical models showed that changing the marginal beam width has an effect on the slab ultimate loads. Since the ultimate loads decreased by $\sim 13 \%$ by changing the marginal beam width from $200 \mathrm{~mm}$ to $150 \mathrm{~mm}$. Also, that load is decreased by $\sim 30 \%$ by changing the marginal beam width from $200 \mathrm{~mm}$ to $100 \mathrm{~mm}$.

\section{REFERENCES}

[1] ISIS-Canada (Reinforcing Concrete Structures with Fibre Reinforced Polymers), Design manual no.3, sep 2007.

[2] "The behavior of fiber-reinforced polymer reinforcement in low temperature environmental climates" by Renee Cusson and Yunping Xi , 2002

[3] "Bond Behavior of Fiber Reinforced Polymer Bars under Direct Pullout Conditions" by Zenon Achillides and Kypros Pilakoutas (2005).

[4] "Evaluation of FRP as Reinforcement for Concrete Bridges"by A. H. Rahman, D. A. Taylor, and C. Y. Kingsley

[5] American Concrete Institute (ACI) State-of-the-Art Report (1996), " Fiber Reinforced Plastic (FRP) Reinforced for Concrete Structures" report by ACI Committee. 440.

[6] American Concrete Institute (ACI) Committee 440, [2006]. "Guide for the Design and Construction of Concrete Reinforced with FRP Bars" ACI 440.1R-06, Farmington Hills, Mich.

[7] ASTM, [2006], "Standard Test Method for Tensile Properties of Fiber Reinforced Polymer Matrix Composite Bars,” D7205/D7205M-06, West Conshohocken, Pa.

[8] ASTM, [2008], "Standard Test Method for Compressive Properties of Polymer Matrix Composite Materials with Unsupported Gage Section by Shear Loading," D3410/D3410M-03, West Conshohocken, Pa.

[9] American Concrete Institute (ACI) Committee 440, (2008). "Specification for Carbon and Glass Fiber-Reinforced Polymer (FRP) Bar Materials for Concrete Reinforcement" ACI 440.6M-08, Farmington Hills, Mich.

[10] Xiao, Y., [2004]. "Applications of FRP Composites in Concrete Columns". Journal of Advances in Structural Engineering, 7(4), 335-343.

[11] Benmokrane B., Zhang B. and Chennouf A. (2000), "Tensile properties and pullout behavior of AFRP and CFRP rods grouted anchor applications "Construction and Building Materials 14, Elsevier Science Ltd. 2000, pp 157-170.

[12] Canadian Standards Association (CSA), (2010). "Specification for Fiber Reinforced Polymers", CAN/CSA S807-10, Rexdale, Ontario, Canada, 44 p.220. 